\title{
Life cycle assessment of conversion processes for the large-scale underground storage of electricity from renewables in Europe
}

\author{
Alfonso Arias Pérez ${ }^{1, \mathrm{a}}$ and Thomas Vogt ${ }^{2, \mathrm{~b}}$ \\ ${ }^{1}$ Instituto Costarricense de Electricidad (ICE), Power Plants Engineering - Design department, \\ Costa Rica \\ ${ }^{2}$ NEXT ENERGY - EWE Research Centre for Energy Technology at the University of Oldenburg, \\ Carl-von-Ossietzky-Str.15, 26129 Oldenburg, Germany
}

\begin{abstract}
This study estimates the total storage capacity for renewable energies in European salt caverns up to the year 2030 in order to deal with the fluctuation of renewable energies. The round-trip efficiencies and the $\mathrm{CO}_{2}$ equivalent direct emissions of the different storage process stages are taken into account. These are transmission, electricity to gas conversion, storage and re-electrification from gas to electricity, of three different energy carriers, namely compressed air, hydrogen and renewable methane.
\end{abstract}

\section{Introduction}

The market for electricity from renewable energies is growing very fast. The main problem of the high renewable share in the energy system is to include the fluctuating production of renewable energy into a system that changes instantly by demand. Extending the electrical transmission grid or the gas distribution grid, building an overcapacity of renewable energy generation, dealing with a fossil-based back up capacity, or increasing the energy storage capacity are just some of the alternatives to deal with fluctuating energies.

Due to the need of large storage capacities for daily, weekly, or even seasonal storage, only alternatives of high energy densities are suitable. Europe, especially Germany, offers a high potential of natural storage in its underground salt domes. With all salt caverns scheduled to be developed by 2030 (as mentioned in the IGU database [1]), the total work-gas volume capacity of Germany will be about 20.000 million normal $\mathrm{m}^{3}$ (around 30.000 million of normal $\mathrm{m}^{3}$ in Europe). The question of how much storage will be required remains. By assuming to generate power by a $100 \%$ from wind and solar, Heide et al. [2] estimated the required energy storage capacity on basis of a simplified European scenario. The necessary maximum of stored energy would be 1.5 times the monthly load without storage losses and

\footnotetext{
a e-mail: aariasp@ice.go.cr

b e-mail: thomas.vogt@next-energy.de
}

This is an Open Access article distributed under the terms of the Creative Commons Attribution License 4.0, which permits unrestricted use, distribution, and reproduction in any medium, provided the original work is properly cited. 
amounts up to $400 \mathrm{TWh}$. By running the same scenario, approximately $500 \mathrm{TWh}$ will be required in Europe by 2030 .

In order to estimate how much energy can be stored in the European salt caverns by 2030, it is also important to assess the possible energy sources. According to the figures released by the Center for Wind Energy Research (Heinemann [3]), five North Sea countries, which are located near the salt domes (Belgium, Denmark, Germany, Netherlands, and the United Kingdom), will be able provide an offshore wind capacity of $78 \mathrm{GW}$. The resulting amount of energy is assumed to be available for the underground storage of renewable energy in 2030 throughout this investigation.

\section{Research question and main objective}

Considering all the previously mentioned renewable resources as well as the storage capacity, estimated to be available/required in 2030, the next logical question will be: What may be the more efficient and ecologically friendly pathway to provide balancing power in 2030 in terms of greenhouse gas emissions for a future large-scale underground storage of renewable energy? By showing the results of the master thesis performed, the present article tries to answer this question. The main objective of the thesis is to compare different energy carriers, namely compressed air, hydrogen and methane through a Life Cycle Assessment (LCA) according to EN ISO 14040 and 14044 [4, 5], time horizon: the year 2030. These energy carriers are stored in the salt caverns by using the following storage technologies, which define the main scenarios in the present analysis:

- Advanced adiabatic compressed air energy storage (AA-CAES)

- Hydrogen energy storage (HES)

- Renewable methane energy storage (MES).

\section{Methodology}

LCA is a standardised methodology used to compile and evaluate the inputs, outputs, and potential environmental impacts of a product system comprised of four main steps:

- Goal and scope definition

- Inventory analysis

- Impact assessment

- Interpretation.

For more information about the methodology of LCA, please refer to the 14040 and 14044 ISO standards [4,5]. This article mentions only the most remarkable results of the total five different scenarios and 11 sensitivity scenarios that have been analysed in the thesis in order to assess the cumulated energy demand (CED in $\mathrm{MWh})$ and direct greenhouse gas emissions $\left(\mathrm{CO}_{2}\right.$-eq. in $\left.\mathrm{kg}\right)$ to provide the functional unit (FU). This FU was defined as $1 \mathrm{MWh}$ of electricity to provide the balancing power for grid services in times of lacking wind energy. Among others, some important limitations, defined in the scope of LCA, are:

- Only $\mathrm{CO}_{2}$ and $\mathrm{CH}_{4}$ direct emissions are considered

- Only cradle-to-usage analysis, no decommissioning of plants

- The calculations have been performed by considering all technologies state-of-the-art for the according time horizon, i.e. 2030.

The stages throughout the different pathways have been classified into five main process segments in order to make the comparison between the alternatives more simple. The first process segment, electricity transmission, is common to all scenarios and takes into account the impacts of the electricity 


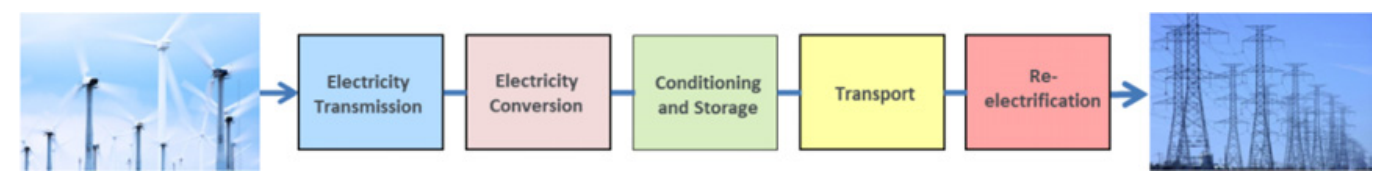

Figure 1. Segmentation of the overall process chain in process steps.

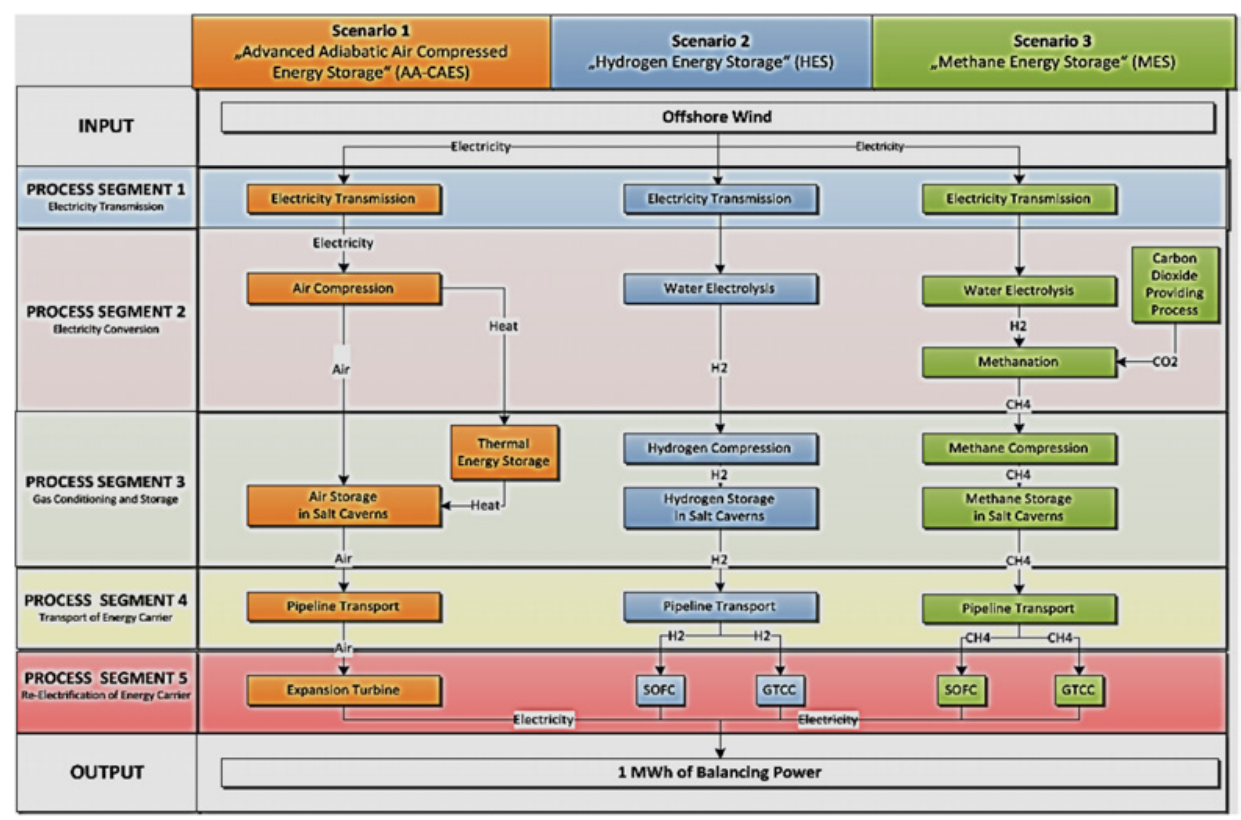

Figure 2. Different routes to convert electricity produced from wind energy offshore farms into stored gas i.e. storage of methane, hydrogen and compressed air. After the compression process, the three compressed gases of the three possible routes are being sent to the storage caverns and are being re-electrified by the grid, when needed.

transmission from the offshore wind plants to the storage plant. The second process segment, electricity conversion, includes the main energy conversion process or processes, from electricity to one of the three energy carriers. The third process segment, gas conditioning and storage, includes all parallel processes necessary for the conditioning and the storage of the gas in the caverns, e.g. hydrogen/methane compression, thermal storage, etc. The $4^{\text {th }}$ process segment includes all gas leakages and pressure losses due to the gas transport through pipelines. Finally, the re-electrification segment, accounts for the impacts during the conversion of the energy carriers into useful electricity.

Figure 2 presents the scheme that shows the processes which are part of the different routes. The first pathway, AA-CAES, regards to atmosphere air, compressed by means of electricity generated by offshore wind plants, and its storage in salt caverns. The heat, produced during the compression, is considered a by-product and is stored to be reused during the re-electrification which works by air expanders (turbines). The hydrogen alternative uses an electrolyser to split water into hydrogen and oxygen. The energy which is necessary for the electrolyser as well as for the hydrogen compression is supplied by the offshore wind power plants. To convert the gas into electricity, the re-electrification draws on a solid oxide fuel cell (SOFC) or on a hydrogen gas turbine combined cycle (GTCC).

Finally, the methane option is very similar to the previous one, but the hydrogen produced by using the electrolysers is combined with carbon dioxide by means of the methanation process (also known 
Table 1. Main assumptions and references.

\begin{tabular}{|c|c|c|c|}
\hline & Value & Unit & Reference \\
\hline Compression efficiency & 84,5 & $\%$ & {$[6]$} \\
\hline Air transport losses & 4 & $\%$ & [7] \\
\hline Expansion efficiency & 89,5 & $\%$ & [6] \\
\hline Shaft mechanical efficiency & 99,5 & $\%$ & [6] \\
\hline Generator/motor efficiency & 98,5 & $\%$ & [6] \\
\hline TES efficiency & 90 & $\%$ & [8] \\
\hline Cavern wellhead pressure, max., charging for air & 60 & bar & [7] \\
\hline Cavern wellhead pressure, min., discharging for air & 40 & bar & [7] \\
\hline Electrolyser efficiency (LHV) & 73 & $\%$ & [9] \\
\hline Hydrogen compression efficiency & 98 & $\%$ & [10] \\
\hline Hydrogen transport losses & 2,4 & $\%$ & [11] and [12] \\
\hline Cavern wellhead pressure, max., charging for $\mathrm{H}_{2} \& \mathrm{CH}_{4}$ & 180 & bar & {$[7]$} \\
\hline Cavern wellhead pressure, min., discharging for $\mathrm{H}_{2} \& \mathrm{CH}_{4}$ & 60 & bar & [7] \\
\hline Methanation efficiency (LHV) & 83,3 & $\%$ & [13] \\
\hline Methane compression efficiency & 96,4 & $\%$ & {$[11]$} \\
\hline Transport losses & 0,8 & $\%$ & [11] and [12] \\
\hline CCGT efficiency (LHV) & 63 & $\%$ & {$[14]$} \\
\hline SOFC efficiency (LHV) & 70 & $\%$ & [15] \\
\hline Cavern wellhead pressure, max., charging & 180 & bar & [7] \\
\hline Cavern wellhead pressure, min., discharging & 60 & bar & [7] \\
\hline
\end{tabular}

as "power to gas") in order to produce synthetic methane. Table 1 lists the main assumptions and their source for transparency and future referencing.

Several possible sources of carbon dioxide for the methanation process gave birth to additional scenarios, where $\mathrm{CO}_{2}$ was obtained through carbon capture and sequestration (CCS) processes from atmospheric air, a GTCC power plant, or a new supercritical pulverised coal power plant (PC). The source of the input product carbon dioxide $\left(\mathrm{CO}_{2}\right.$ as a product) for the methanation process was investigated and included into the calculations based on the energy requirements for carbon capture and sequestration (CCS) from [16] and [17].

The effect on the direct emissions by including a $\mathrm{CO}_{2}$-recycling process after the re-electrification was investigated for the methanation scenario with a CCS process applied to a GTCC power plant (3-Ib_MES-SOFC_CCS-GTCC), considering 90\% and 97\% capture efficiencies according to [16] for the $\mathrm{CO}_{2}$ recycling. All $\mathrm{CO}_{2}$ recovered in the CCS process was assumed to be reincluded into the methanation process. The $\mathrm{CO}_{2}$ that was not recovered was supposed to be obtained from a NGCC power plant with an integrated CCS. The energy needed for the total CCS per $\mathrm{kg}$ of $\mathrm{CO}_{2}$ was assumed to be the same; the total mass of $\mathrm{CO}_{2}$ needed for the methanation process was not affected by the $\mathrm{CO}_{2}$ source.

\section{Main results}

\subsection{Efficiency}

Figure 3 shows the efficiency decrease of the eight most representative scenarios as the processes follow the steps of the different pathways. With almost 63\%, AA-CAES is the most energy efficient process. The second place takes the hydrogen storage processes with efficiencies of 48\% (2-I_HES-SOFC) and $43 \%$ (2-II_HES-GTCC) using SOFC and GTCC for re-electrification, respectively. The lowest values of efficiency have been obtained from the methane scenarios, starting with the one that uses SOFC for re-electrification (3-I_MES-SOFC) with a roundtrip total efficiency of $40 \%$ followed by the scenario that uses a GTCC for re-electrification (3-II_MES-GTCC) yielding 36\%. By taking the source of $\mathrm{CO}_{2}$ into account, the efficiency of CCS from atmospheric air (3-I_MES-SOFC_CCS-Air) drops to 26\%. 

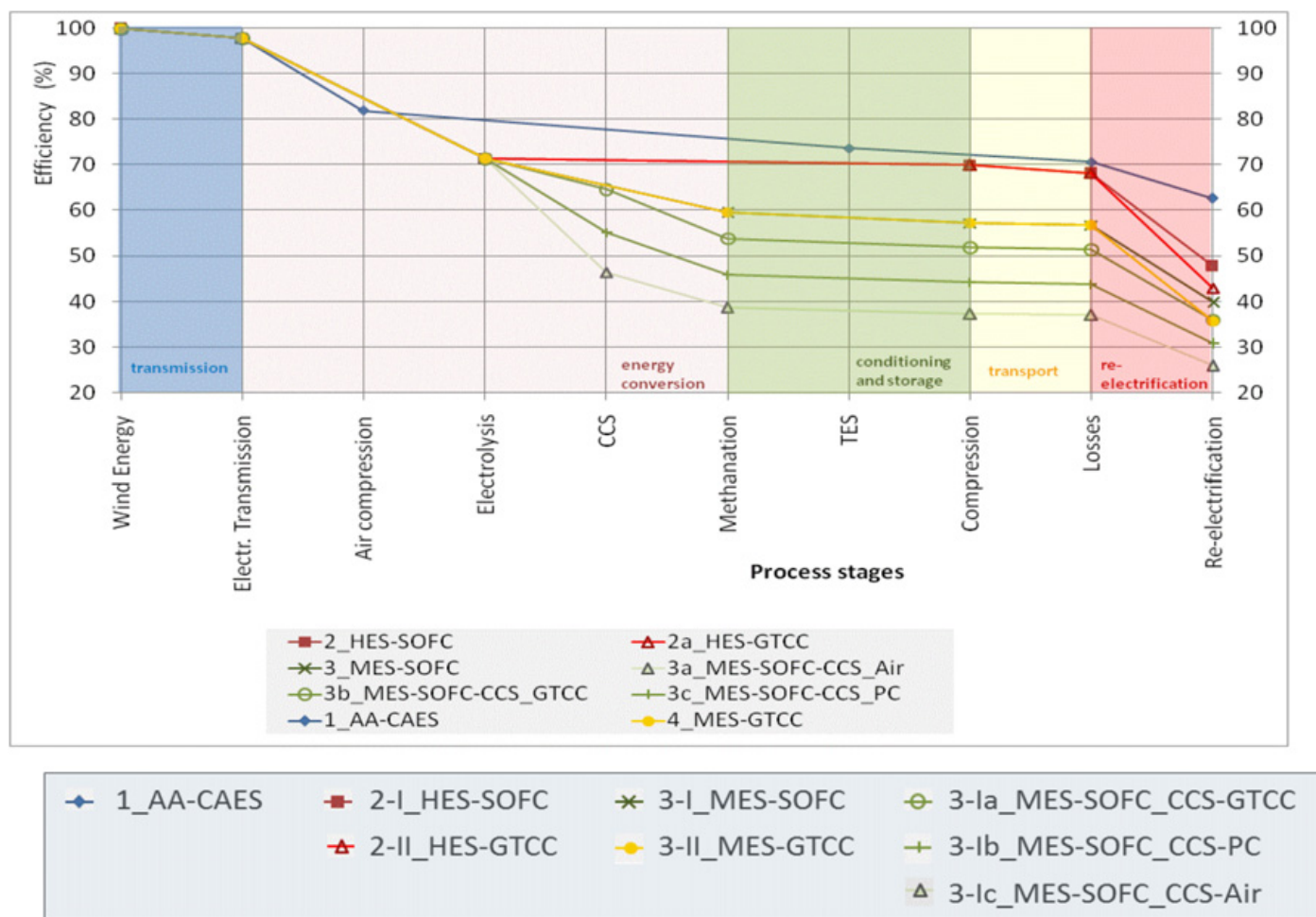

Figure 3. Decrease of efficiency of 8 representative scenarios through the process segments.

The efficiency of CCS applied to a GTCC plant (3-I_MES-SOFC_CCS-GTCC) drops to to 36\% and the CCS efficiency in a new supercritical pulverized coal power plant drops to $31 \%$.

The energy conversion and re-electrification segments are more crucial as they need most energy. The processes taking place in AA-CAES (air compression), HES (electrolysis) and MES (electrolysis and methanation) should be improved to higher round-trip efficiencies, in future. The development of high temperature electrolysis (HTE) [18] provides the opportunity for good improvement, given that the technology will be state-of-the-art in the considered time horizon. As for re-electrification, the expected rise of efficiencies in GTCC is not that optimistic. Its efficiency is expected to rise very slowly. It will probably reach $63 \%$ by 2030 [14].

\subsection{Direct emissions}

Figure 4 depicts the comparison between the direct emissions. An important fact is that no direct emissions of equivalent carbon dioxide arise in AA-CAES and HES. As for the MES scenarios, the direct emissions depend on the CCS application at the end of the re-electrification process. The emissions in the GTCC for re-electrification scenario could be considerably reduced by recycling $\mathrm{CO}_{2}$ with capture efficiencies of $90 \%$ and $97 \%$. The total emissions for the MES scenario using a GTCC in the re-electrification stage is $337,9 \mathrm{~kg}$ of $\mathrm{CO}_{2}$ equivalent per $\mathrm{MWh}_{\mathrm{e}}$. The emissions for the rest of the MES scenarios are $304,1 \mathrm{~kg}$ of $\mathrm{CO}_{2}$ equivalent per $\mathrm{MWh}_{e}$. If a CCS system is integrated at the end of the re-electrification stage the values are $37,4 \mathrm{~kg}$ of $\mathrm{CO}_{2}$ equivalent per $\mathrm{MWh}_{\mathrm{e}}$ and $16,7 \mathrm{~kg}$ of $\mathrm{CO}_{2}$ equivalent per $\mathrm{MWh}_{\mathrm{e}}$ for CCS efficiencies of $90 \%$ and $97 \%$ respectively. 


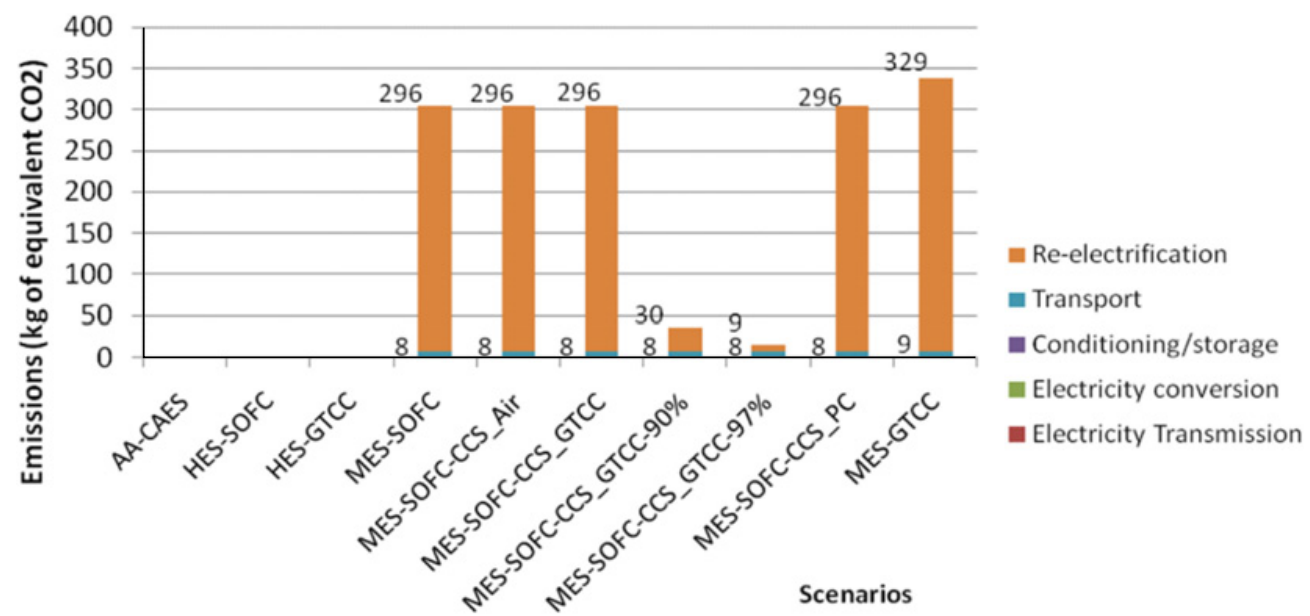

Figure 4. Comparison of scenarios regarding the release of direct emissions from $\mathrm{CO}_{2}$ and $\mathrm{CH}_{4}$ in terms of $\mathrm{kg}$ of equivalent $\mathrm{CO}_{2} / \mathrm{MWh}$ of electricity. As a reference, according to [16] approximately $344 \mathrm{~kg}$ of equivalent $\mathrm{CO}_{2}$ per MWh are released by a new GTCC power plant.

Table 2. Storable energy in the salt caverns in 2030.

\begin{tabular}{|l|c|c|c|c|}
\hline Scenario & $\begin{array}{c}\text { Efficiency } \\
(\%)\end{array}$ & $\begin{array}{c}\text { Storage capacity } \\
\text { (energy after re- } \\
\text { electrification in TWh) }\end{array}$ & $\begin{array}{c}\text { Emissions } \\
\text { (kg CO2_eq/MWh) }\end{array}$ & $\begin{array}{c}\text { Suitability for long term } \\
\text { balancing 2030 }\end{array}$ \\
\hline 1_AA-CAES & 62,7 & 0,3 & 0 & very low stored energy \\
\hline 2-I_HES-SOFC & 47,8 & $31,9^{*}$ & 0 & Insufficient storage volume \\
\hline 2-II_HES-GTCC & 43,0 & $28,7^{*}$ & $304(9,1$ with CCS) & Suitable \\
\hline 3-I_MES-SOFC & 39,9 & $137,7^{* *}$ & $304(9,1$ with CCS) & Suitable \\
\hline 3-II_MES-GTCC & 35,9 & $125,9^{* *}$ & $304(9,1$ with CCS) & Suitable \\
\hline 3-la_MES-SOFC_CCS-Air & 25,9 & $137,7^{* *}$ & $304(9,1$ with CCS) & Suitable \\
\hline 3-Ib_MES-SOFC_CCS-GTCC & 36,1 & $137,7^{* *}$ & $304(9,1$ with CCS) & Suitable \\
\hline 3-IC_MES-SOFC_CCS-PC & 30,8 & $137,7^{* *}$ & $304(9,1$ with CCS $)$ & Suitable \\
\hline
\end{tabular}

\subsection{Storable energy in the salt caverns for 2030}

Taking the same time horizon as a basis, some interesting results have been deduced from the energy expected to be produced by means of Europe's salt cavern capacities, scenario efficiencies and offshore wind in 2030. Table 2 presents the most important results of the mainly investigated scenarios.

Considering Europe's limited salt caverns storage volume up to year 2030 and the energy density of the three energy carriers, almost 138 TWh can be stored and re-electrified through the methane energy storage processes, while only 32 TWh can be stored by using hydrogen energy storage. In case of AACAES, the storable energy is even smaller, providing 0,3 TWh, only. In reference to the MES scenarios presented in Table 2, only 117, 76, 106, 90, and 105 TWh, respectively for the figures marked with “**”, can be supplied by $292 \mathrm{TWh} /$ year wind offshore energy in order to fill the total capacity of the caverns, i.e. 137,7 TWh and 125,9 TWh. Consequently, additional sources other than offshore wind energy will be required.

The HES technology could produce 140 TWh by 292 TWh/year wind offshore energy, but only 32 TWh and 29 TWh, respectively (see Table 2, figures marked with “*”), could be stored due to 

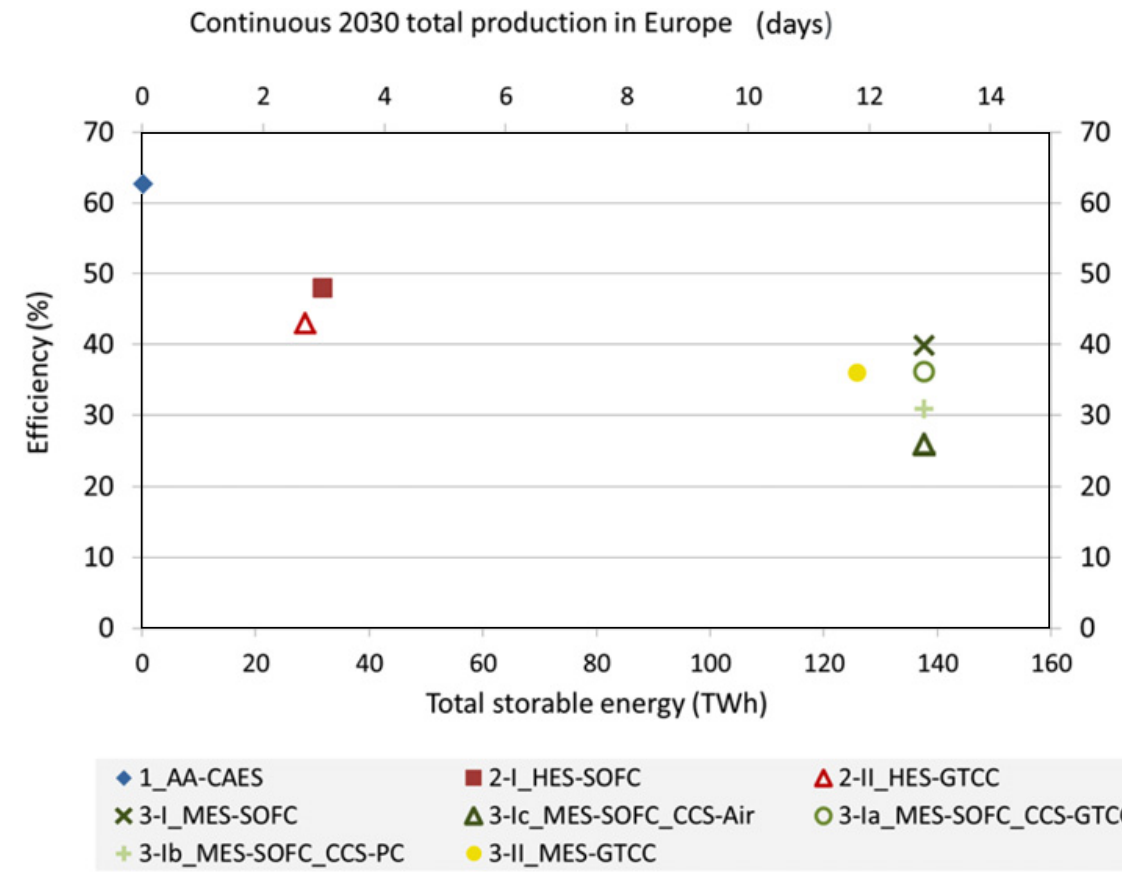

- 2-I_HES-SOFC

$\triangle$ 3-Ic_MES-SOFC_CCS-Air 3-II_MES-GTCC $\triangle$ 2-II_HES-GTCC

O 3-la_MES-SOFC_CCS-GTCC

Figure 5. Comparison of the scenarios considering efficiency against stored energy and days of total European demand supply in 2030 with gas stored in the salt caverns.

the limited volume of the caverns. This is due to the hydrogen's low energy density per volume of cavern storage. By comparing the storage capacity values of Table 2 with the estimated total of required storage of about $500 \mathrm{TWh}$ in 2030, it becomes clear that, in 2030, about 27,5\% of the necessary storage for renewables integration in Europe might be provided by storing methane in the underground salt caverns. Figure 5 shows the relation between the total of storable energy and the round efficiency of the different scenarios. The upper $\mathrm{x}$-axis presents the total time in days by which the European demand for electricity in 2030 could be provided by the energy stored in the salt caverns.

\section{Conclusions}

The AA-CAES technology does not cover middle-term or long-term storage, but it is suitable for hourly grid balancing. Hydrogen storage is suitable for middle-term storage. On basis of the hydrogen scenario, building additional storage capacity or using other types of gas storage (e.g. depleted gas and oil fields or aquifers) should be considered as well.

Strong efforts are necessary to be made on research and the development of HTE in order to simultaneously reach a high efficiency and a commercial level for MES and HES technologies in the hundreds of MW scale. The advantage of this technology is the theoretical capability of high efficiencies similar to the ones of AA-CAES. However, this needs to be translated into real production plants.

From a technical point of view, methane energy storage can be regarded as a suitable option to supply a considerable share of the future European need for balancing power. Our calculations show that almost $28 \%$ of this requirement could base on synthetic methane underground storage in salt caverns. MES might be more infrastructure-friendly considering that less cavern volume is required and that state-ofthe-art systems for transportation and electricity generation of natural gas can be used for renewable methane. This assumption is based on the high content of methane in natural gas [19]. 
However, deeper LCA and Life Cycle Cost analyses are required to give final recommendations. A possible issue regarding renewable methane is the availability of $\mathrm{CO}_{2}$ in a greener energy system in Europe in 2030. Would $\mathrm{CO}_{2}$ be produced as much as it is today? Or will CCS from atmospheric air be the most probable source of this input for the methane production? The hydrogen pathway could be the better option considering the aspects of economy and $\mathrm{CO}_{2}$-availabilty. Furthermore, the hydrogen cycle is of higher efficiency and direct emissions would not be produced anymore.

\section{References}

[1] International Gas Union, Working Committee 2: Storage, 2006 - 2009 Triennium World Report, www . igu .org, http://www. igu .org/html/wgc2009/committee/WOC2/WOC2 . pdf (2009)

[2] D. Heide, L. von Bremen, M. Greiner, C. Hoffmann, M. Speckmann, S. Bofinger, Renewable Energy, Seasonal optimal mix of wind and solar power in a future, highly renewable Europe, November, 2483-2489 (2010)

[3] D. Heinemann, Personal Interview by A. Arias and T. Vogt, Forwind (2012)

[4] ISO/TC 207, ISO 14040:2006, Environmental management - Life cycle assessment - Principles and framework (2006)

[5] ISO/TC 207, ISO 14044, Environmental management - Life cycle assessment - Requirements and guidelines (2006)

[6] S. Freund, R. Schainker, R. Moreau, Commercial concepts for adiabatic compressed air energy storage, 7th Renewable Energy Storage Conference. Berlin, Germany: Eurosolar 2012

[7] F. Crotogino, interview by A. Arias, Niedersachsen (February 2013)

[8] M. Hänchen, S. Brücker, A. Steinfeld, High temperature thermal storage using a packed bed of rocks - Heat transfer analysis and experimental validation, Applied Thermal Engineering, 1798-1806 (2011)

[9] T. Smolinka, M. Günther, J. Garche, NOW Studie: Stand und Entwicklungspotenzial der Wasserelektrolyse zur Herstellung von Wasserstoff aus regenerativen Energien, Nationale Organisation Wasserstoff- und Brennstoffzellentechnologie (NOW), Fraunhofer ISE, FCBAT, Germany (2010)

[10] M. Gardiner, DOE Hydrogen and Fuel Cells Program Record, Department of Energy (2009)

[11] U. Bossel, B. Eliasson, G. Taylor, The Future of the Hydrogen Economy: Bright or Bleak? Switzerland, United Kingdom (2003)

[12] T. Feck, Wasserstoff-Emissionen und ihre Auswirkungen auf den arktischen Ozonverlust, Forschungszentrum Jülich GmbH. Jülich (2009)

[13] U. Zuberbühler, Contact via web form. Germany (2013)

[14] Y. Kobayashi, Y. Ando, T. Kabata, M. Nishiura, K. Tomida, N. Matake, Extremely High-Efficiency Thermal Power System-Solid Oxide Fuel Cell (SOFC) Triple Combined-cycle System, Mitsubishi Heavy Industries Technical Review, September (2011)

[15] R. Steinberger-Wilckens, Interview, Oldenburg (2012)

[16] Working Group III of the Intergovernmental Panel on Climate Change, IPCC Special Report on Carbon Dioxide Capture and Storage (2005)

[17] M. Sterner, Bioenergy and renewable power methane in integrated 100\% renewable energy systems, Vol. Renewable Energies and Energy Efficiency 14 (2009)

[18] D. Stolten, Hydrogen and Fuel Cells: Fundamentals, Technologies and Applications, Germany (2010)

[19] E. Rummich, Energiespeicher - Grundlagen, Komponenten, Systeme und Anwendungen (2009) 